\title{
Parental motivation to change body weight in young overweight children
}

\author{
Rachael W Taylor ${ }^{1, *}$, Sheila M Williams ${ }^{2}$, Anna M Dawson ${ }^{3}$, Jillian J Haszard ${ }^{4}$ and \\ Deirdre A Brown ${ }^{5}$ \\ 'Department of Medicine, University of Otago, PO Box 56, Dunedin 9054, New Zealand: '²Department of \\ Preventive and Social Medicine, University of Otago, Dunedin, New Zealand: ${ }^{3}$ Department of Women's and \\ Children's Health, University of Otago, Dunedin, New Zealand: ${ }^{4}$ Department of Human Nutrition, University of \\ Otago, Dunedin, New Zealand: ${ }^{5}$ School of Psychology, Victoria University of Wellington, Wellington, New Zealand
}

Submitted 28 October 2013: Final revision received 30 June 2014: Accepted 2 September 2014: First published online 7 October 2014

\begin{abstract}
Objective: To determine what factors are associated with parental motivation to change body weight in overweight children.

Design: Cross-sectional study.

Setting: Dunedin, New Zealand.

Subjects: Two hundred and seventy-one children aged 4-8 years, recruited in primary and secondary care, were identified as overweight (BMI $\geq 85$ th percentile) after screening. Parents completed questionnaires on demographics; motivation to improve diet, physical activity and weight; perception and concern about weight; parenting; and social desirability, prior to being informed that their child was overweight. Additional measures of physical activity (accelerometry), dietary intake and child behaviour (questionnaire) were obtained after feedback.

Results: Although all children were overweight, only $42 \%$ of parents perceived their child to be so, with $36 \%$ indicating any concern. Very few parents ( $n$ 25, $8 \%$ ) were actively trying to change the child's weight. Greater motivation to change weight was observed for girls compared with boys $(P=0 \cdot 001)$, despite no sex difference in BMI $Z$-score $(P=0.374)$. Motivation was not associated with most demographic variables, social desirability, dietary intake, parenting or child behaviour. Increased motivation to change the child's weight was observed for heavier children $(P<0.001)$, those who were less physically active $(P=0.002)$ and more sedentary $(P<0.001)$, and in parents who were more concerned about their child's weight $(P<0 \cdot 001)$ or who used greater food restriction $(P<0 \cdot 001)$.

Conclusions: Low levels of parental motivation to change overweight in young children highlight the urgent need to determine how best to improve motivation to initiate change.
\end{abstract}

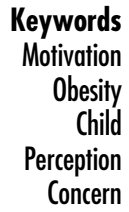

Effective treatment of obesity in children requires parents to recognise that excess weight is an issue and be motivated to make lifestyle changes to improve weight. This is potentially more successful at younger ages when parents maintain some control over the family food and activity environment and before lifestyle habits have become entrenched $^{(1)}$. Unfortunately it is well established that parents of young children do not recognise overweight in their offspring ${ }^{(2,3)}$. In fact, excess weight may only be viewed as a concern once it is at the level of impeding physical functioning or the child is being bullied about his/her size ${ }^{(4)}$.

Concepts central to motivation include perceived importance of the issue, confidence to change and the ability to actually do so ${ }^{(5)}$. However, while motivation is regarded as a critical prerequisite for encouraging behaviour change ${ }^{(6)}$, factors that may influence parental motivation for changing their child's weight have rarely been studied. Research to date suggests that parents categorised as making preparations for, or actively engaged in, change are more likely to have older children, believe that their child's weight is a health problem or be overweight themselves, compared with parents who are not interested in change ${ }^{(7)}$. Even when parents of obese children indicate strong concern about their child's weight (importance) and are ready to make diet and activity changes (readiness), their confidence in their ability to actually do so is markedly lower ${ }^{(8)}$. This has important 
implications for success given that confidence in the ability to do well is a significant predictor of treatment completion and early weight loss, whereas importance and readiness are not related ${ }^{(9)}$. Parental motivation for weight loss is also known to be a predictor of treatment uptake $^{(10,11)}$. How to increase motivation is therefore of importance, yet we know little about what factors determine motivation in parents for changing weight in their overweight children.

Motivation can be measured in a variety of ways. The Motivational Screening Measure (MSM) was developed as a simple tool to quickly assess motivation for behaviour change in the clinical setting. The MSM consists of three questions which assess key facets of motivation: importance, ability and commitment to change the behaviour of interest ${ }^{(5)}$. We recently undertook a major weightscreening initiative where we measured parental motivation for changing weight in young children prior to knowledge about the child's weight status ${ }^{(12)}$. The aim of the present study was to determine what factors were associated with parental motivation to change body weight in a community sample of children aged $4-8$ years identified as overweight through screening.

\section{Experimental methods}

The present analysis involved Phase 1 of our Motivational Interviewing and Treatment (MInT) study ${ }^{(13)}$, which assessed parental responses to different styles of weight feedback after a weight-screening initiative ${ }^{(12)}$. The study has previously been described in detail ${ }^{(13)}$, but information relevant to the present analysis is described here. Ethical approval was obtained from the Lower South Regional Ethics Committee (LRS/09/09/039) and all parents gave informed consent.

\section{Health check appointment}

All families with children aged 4-8.99 years enrolled at nine participating general practices were invited to participate in a comprehensive health check. Recruitment occurred from March 2010 until August 2011. Children of the same age, not already enrolled at any of these practices, who attended secondary care clinics across two time periods (March 2009-March 2010 and January 2011May 2011) were also invited to attend. Children were excluded if they had severe childhood arthritis, severe asthma, cystic fibrosis, inflammatory bowel disease, congenital or chromosomal abnormalities, severe developmental delay or were on medication that may influence body composition, or if their families were not planning to remain in the region for the next two years.

Duplicate measures of height (Tanita portable stadiometer) and weight (Tanita BC-418) were obtained following standard techniques. BMI was derived and $Z$-scores calculated ${ }^{(14)}$. Questionnaires on demographics, motivation, parenting, social desirability and beliefs about the child's weight were completed before the parents were informed of the weight status of their child. Household structure, child ethnicity and socio-economic status were assessed using questions from the New Zealand census (www.stats.govt.nz). Socio-economic status was determined using the New Zealand Deprivation index (NZDep), which is a measure of deprivation assigned to an area based on population criteria such as income, housing and qualifications ${ }^{(15)}$. Maternal height and weight were measured in duplicate at the health check appointment where possible ( $49 \%)$, were self-reported (48\%) or missing (3\%).

Miller and Johnson's ${ }^{(5)}$ MSM assessed three constructs of motivation in parents, namely importance ('It is important for me to...'), ability ('I could...') and commitment ('I am trying to...'), in relation to three behaviours: increasing their child's physical activity, improving their child's diet or changing their child's weight. Each of the nine questions was answered on an 11-point scale, where: 0 and $1=$ 'definitely not'; 2,3 and $4=$ 'probably not'; $5=$ 'maybe'; 6 , 7 and $8=$ 'probably'; and 9 and $10=$ 'definitely'. Parental feeding practices thought to influence child weight were assessed using five constructs ${ }^{(16)}$ from the Comprehensive Feeding Practices Questionnaire ${ }^{(17)}$. Parenting practices were indicated by the Parenting Scale ${ }^{(18)}$, with higher scores indicating more ineffective parenting practices (possible range: 1-7). For example, in response to "When I give a fair threat or warning...' the parent would indicate 'I often don't carry it out' (score of 7) compared with 'I always do what I said' (score of 1). Social desirability was assessed in a random sample of participants using the thirteen-item short form of the Marlowe-Crowne Social Desirability Scale, with higher scores indicating more socially desirable responses ${ }^{(19)}$. Parental concern for the child's weight was based on a 5-point Likert scale ( $1=$ 'not at all concerned', $5=$ 'very concerned'), and parents were also asked to rate their child's weight on a 5-point scale ('a little underweight', 'underweight', 'normal weight', 'a little overweight', 'overweight').

\section{Baseline intervention appointment}

A total of 1093 children underwent screening, of whom 271 were classified as overweight (BMI $\geq 85$ th percentile of US reference data) ${ }^{(14)}$. Parents of these children were randomised to receive information about their child's weight status using motivational interviewing or best practice care, and were subsequently invited into a twoyear intervention ${ }^{(12)}$. Those agreeing to participate ( $n$ 203, $75 \%)$ attended an additional appointment where the following measures were obtained. Dietary intake was assessed using the Children's Dietary Questionnaire ${ }^{(20)}$, a twenty-nine-item questionnaire which yields three subscales of interest. Parents completed the CHAOS (Confusion, Hubbub and Order Scale) questionnaire, with yes or no answers to fifteen items about structure within the 
home such as 'there is very little commotion in our home'. Higher scores indicate a greater level of household chaos $^{(21)}$. Parents also completed the Lifestyle Behaviour Checklist, which asks parents to rate the extent to which they experience twenty-five weight-related behaviours in their child (e.g. eating unhealthy snacks, refusing to do physical activity) on a 7-point scale (from 'not at all' to 'very much') ${ }^{(22)}$.

Physical activity and time asleep were measured over seven consecutive days by ActiGraph (GT3X) accelerometers worn $24 \mathrm{~h}$ per day. All sleep time was removed from the files before analysis of physical activity as counts per minute or time in moderate-to-vigorous physical activity $^{(23)}$ was calculated.

\section{Statistics}

Measures on demographics, motivation, parenting and beliefs about the child's weight were available in all 271 overweight children (from the health check appointment). Measures of diet, physical activity, sleep, chaos and problem behaviours (Lifestyle Behaviour Checklist) were available for 203 of these children (from the baseline intervention appointment). A composite motivation for weight change score was calculated from the average of the three questions from the MSM. Cronbach's $\alpha$ for this composite measure was $0 \cdot 89$.

Data are presented as mean and standard deviation, or as number and percentage, as appropriate. Differences between groups were compared using independent $t$ tests. Univariate and multivariate regression analysis was used to determine which factors were related to the composite motivation for weight change score. All analyses were undertaken using the statistical software package Stata release 12 .

\section{Results}

Table 1 presents the demographic characteristics of the study population. The sample was predominantly European, but included a higher proportion of ethnic minority children than is typically observed in the local population (NZ Census, 2006). Although this was a well-educated sample (one-third of mothers with a university degree), a wide range of socio-economic status was still observed.

Table 1 Characteristics of the study population: children $(n 271)$ aged $4-8$ years, recruited in primary and secondary care, and their parents, Dunedin, New Zealand, March 2010-August 2011

\begin{tabular}{|c|c|c|c|}
\hline Variable & $N$ & Mean or $n$ & SD or $\%$ \\
\hline Age (years), mean and SD & 271 & $6 \cdot 4$ & 1.4 \\
\hline Female, $n$ and $\%$ & 271 & 150 & 55 \\
\hline Ethnicity, $n$ and $\%$ & 270 & & \\
\hline New Zealand European and others & & 200 & 74 \\
\hline Maori & & 50 & 19 \\
\hline Pacific Islander & & 20 & 7 \\
\hline Level of household deprivation, $n$ and $\%$ & 262 & & \\
\hline High & & 71 & 27 \\
\hline Medium & & 94 & 36 \\
\hline Low & & 97 & 37 \\
\hline Maternal education, $n$ and $\%$ & 268 & & \\
\hline Secondary only & & 105 & 39 \\
\hline Tertiary but not university degree & & 56 & 21 \\
\hline University degree & & 91 & 34 \\
\hline Other & & 16 & 6 \\
\hline Maternal BMI $\left(\mathrm{kg} / \mathrm{m}^{2}\right)$, mean and SD & 258 & $29 \cdot 1$ & $6 \cdot 2$ \\
\hline Child BMI Z-score, mean and SD & 271 & 1.61 & 0.45 \\
\hline Child weight status, $n$ and $\%$ & 271 & & \\
\hline Overweight & & 166 & 61 \\
\hline Obese & & 105 & 39 \\
\hline Social desirability, mean and SD & 139 & 8.6 & $2 \cdot 4$ \\
\hline Ineffective parenting practices, mean and SD & 270 & $2 \cdot 8$ & 0.6 \\
\hline Chaos score, mean and SD & 202 & $3 \cdot 3$ & $3 \cdot 1$ \\
\hline Lifestyle behaviour checklist score, mean and SD & 201 & 49 & 16 \\
\hline Restriction of food, mean and SD & 271 & $2 \cdot 2$ & 0.7 \\
\hline \multicolumn{4}{|l|}{ Dietary intake, mean and SD } \\
\hline Fruit and vegetable score & 202 & $13 \cdot 8$ & 4.0 \\
\hline Non-core foods score & 197 & $2 \cdot 5$ & 0.9 \\
\hline Sweetened beverages score & 202 & 0.9 & $1 \cdot 2$ \\
\hline \multicolumn{4}{|l|}{ Accelerometry data, mean and SD } \\
\hline Counts per minute & 197 & 640 & 193 \\
\hline MVPA (h/d) & 197 & 0.5 & 0.3 \\
\hline Sedentary time $(\mathrm{h} / \mathrm{d})$ & 197 & $9 \cdot 2$ & $1 \cdot 2$ \\
\hline Perceived physical activity by child ${ }^{*}$, mean and SD & 271 & $3 \cdot 1$ & 0.9 \\
\hline
\end{tabular}

MVPA, moderate-to-vigorous physical activity.

Data are presented as mean and standard deviation, or as number and percentage, as appropriate.

*On a scale where $1=$ 'much less active' and $5=$ 'much more active' than children of the same age and sex. 
Table 2 Parental motivation scores for changing the dietary intake, physical activity participation and body weight of their overweight child ( $n$ 271), Dunedin, New Zealand, March 2010-August 2011

\begin{tabular}{|c|c|c|}
\hline MSM question* & Mean & SD \\
\hline It is important that my child eats a healthy diet & $9 \cdot 3$ & $1 \cdot 2$ \\
\hline I could improve my child's diet & $7 \cdot 3$ & $2 \cdot 3$ \\
\hline I am trying to improve my child's diet & $6 \cdot 9$ & $2 \cdot 7$ \\
\hline It is important to me that my child is physically active & $9 \cdot 3$ & 1.0 \\
\hline I could increase the amount of physical activity my child does & $7 \cdot 3$ & $2 \cdot 0$ \\
\hline I am trying to increase the amount of physical activity my child does & $6 \cdot 3$ & $2 \cdot 5$ \\
\hline It is important that I change my child's weight & 3.5 & 3.1 \\
\hline I could change my child's weight & 4.8 & $2 \cdot 9$ \\
\hline I am trying to change my child's weight & 3.2 & 3.3 \\
\hline Composite motivation for changing weight score & 3.8 & $2 \cdot 8$ \\
\hline
\end{tabular}

MSM, Motivational Screening Measure.

*Using a scale from 0 ('definitely not') to 10 ('definitely').

Not surprisingly, maternal BMI was high in this sample of overweight (61\%) and obese (39\%) children.

Table 1 also reports the mean values for the various lifestyle factors of interest in this sample. Overall, parents within the sample reported low levels of chaos within the home (mean score of 3.3 from a total maximum of 15 ) and a low rate of ineffective parenting practices (mean score of $2 \cdot 8$ from a total maximum of 7 ). Scores obtained from the social desirability questionnaire spanned the entire range (0-13) with a mean score of $8 \cdot 6$, indicating that social desirability was present within this group. Fruit and vegetable intake was relatively close to the recommended level (14), but children ate more non-core foods than is advised (recommended two or less). However, sweetened drink intake was below the recommended level. Accelerometry data indicated that this was a sedentary group, with children spending more than $9 \mathrm{~h} / \mathrm{d}$ in sedentary activities and only $33 \mathrm{~min} / \mathrm{d}$ in moderate-to-vigorous physical activity.

The majority ( $n 158,58 \%$ ) of parents rated their child as normal weight, with ninety (33\%) saying their child was a little overweight and a further twenty-three ( $8 \%$ ) reporting the child as overweight. Only ninety-six parents (36\%) were concerned about their child's weight, with parents being significantly more concerned about girls compared with boys $(P=0 \cdot 036)$, despite no significant sex difference in BMI $Z$-scores $(P=0.374)$. Table 2 presents the findings from the MSM. Parents were clearly more motivated for children to have a healthy diet or be more physically active than to change their body weight, despite all children being overweight or obese. For example, $79-83 \%$ of parents scored 9 or 10 (anchor of 'definitely') for questions assessing the importance of eating healthily or being physically active, compared with only $8 \%$ doing so for changing the child's weight. Similar variation was observed for diet and activity measures of confidence ('I could...') and commitment ('I am trying to...') compared with relevant weight measures (data not shown). Within the weight subscale, confidence in the ability to change children's weight was higher than either importance $(P<0.001)$ or commitment $(P<0 \cdot 001)$. Similarly to weight concern, higher scores were observed for each weight motivation question in girls, indicating that parents seemed to feel it was more important to change their daughter's weight $(P=0 \cdot 001)$ and more were actively trying to do so $(P=0 \cdot 005)$. However, confidence to do so ('I could change their weight') was also higher for girls compared with boys $(P=0 \cdot 002)$. By contrast, sex differences in motivation for improving diet or activity were not apparent (data not shown).

Few demographic variables were related to motivation for changing the child's weight in univariate analyses (Table 3). Although increasing levels of parental motivation were observed in older children and girls, no differences in motivation were apparent by level of household deprivation or maternal BMI. Much stronger positive relationships were observed with the child's actual weight status (BMI $Z$-score, $P<0.001)$ and whether their parents perceived them to be overweight $(P<0 \cdot 001)$ or were concerned about their weight status $(P<0 \cdot 001)$.

Lifestyle was also associated with parental motivation for changing weight (Table 3). Parents reported increased motivation for children who scored higher on the Lifestyle Behaviour Checklist $(P<0.001)$, an indicator of problem behaviours common in overweight children. In total, seventy-nine children (39\%) scored 50 or more on this questionnaire, indicating significant clinical issues ${ }^{(22)}$. More motivated parents also scored higher on the food restriction scale, a parental feeding strategy known to be related to body weight during growth. Motivation for weight change was not related to dietary intake (Table 3), but was higher in parents of children with lower levels of physical activity (accelerometer or questionnaire) or more sedentary time (Table 3). Interestingly, motivation to change the child's weight was not related to social desirability, the degree of perceived chaos within the home or overall ineffective parenting practices.

All variables significant in the univariate analysis were entered in the multivariate model with the exception of ethnicity, as the overall $P$ value was not significant. Separate multiple regression analyses were also undertaken using each of the measures of physical activity 
Table 3 Predictors of parental motivation to alter child's body weight (using composite score for motivation), Dunedin, New Zealand, March 2010-August 2011

\begin{tabular}{|c|c|c|c|c|c|}
\hline & \multicolumn{3}{|c|}{ Univariate models } & \multicolumn{2}{|c|}{ Multivariate models } \\
\hline & $\beta$ & $P$ & $R^{2}$ & $\beta$ & $P$ \\
\hline Age (years) & 0.71 & $<0.001$ & 0.13 & 0.13 & 0.277 \\
\hline Sex (female) & $1 \cdot 15$ & 0.001 & 0.04 & 0.24 & 0.125 \\
\hline Ethnicity ${ }^{\star}$ & 0.13 & 0.509 & 0.03 & & \\
\hline Maori & 0.31 & 0.597 & & & \\
\hline Pacific Islander & 1.80 & 0.028 & & & \\
\hline \multicolumn{6}{|l|}{ Level of household deprivation† } \\
\hline Medium & 0.23 & 0.536 & & & \\
\hline High & -0.37 & 0.588 & & & \\
\hline Maternal education $\ddagger$ & 0.08 & 0.641 & 0.01 & & \\
\hline Tertiary but not university degree & 0.02 & 0.963 & & 0.36 & 0.271 \\
\hline University degree & -0.12 & 0.778 & & -0.12 & 0.696 \\
\hline Other & 1.00 & 0.027 & & -0.60 & 0.211 \\
\hline Maternal BMI $\left(\mathrm{kg} / \mathrm{m}^{2}\right)$ & 0.05 & 0.087 & & & \\
\hline Child BMI Z-score & $3 \cdot 10$ & $<0.001$ & 0.25 & 0.65 & 0.004 \\
\hline Social desirability (1 unit) & 0.08 & 0.395 & & & \\
\hline Concern about child's weight§ & $4 \cdot 30$ & $<0.001$ & 0.54 & 2.41 & $<0.001$ \\
\hline Perceived child's weight status\|ll & 3.65 & $<0.001$ & 0.41 & 1.48 & 0.002 \\
\hline Ineffective parenting practices (1 unit) & 0.12 & 0.464 & & & \\
\hline Chaos score (1 unit) & -0.01 & 0.861 & & & \\
\hline Lifestyle behaviour checklist score (1 unit) & 0.06 & $<0.001$ & 0.10 & -0.00 & 0.716 \\
\hline Restriction of food (1 unit) & 2.09 & $<0.001$ & 0.30 & 0.79 & 0.009 \\
\hline \multicolumn{6}{|l|}{ Dietary intake } \\
\hline Fruit and vegetables score (1 unit) & -0.00 & 0.919 & & & \\
\hline Non-core foods score ( 1 unit) & -0.12 & 0.152 & & & \\
\hline Sweetened beverages score ( 1 unit) & 0.08 & 0.560 & & & \\
\hline \multicolumn{6}{|l|}{ Accelerometry } \\
\hline Counts per minute $(100 \mathrm{cpm})$ & -0.50 & 0.002 & 0.09 & -0.08 & 0.084 \\
\hline $\operatorname{MVPA}(\mathrm{h} / \mathrm{d})$ & $-2 \cdot 35$ & 0.001 & 0.06 & & \\
\hline Sedentary time $(\mathrm{h} / \mathrm{d})$ & 0.67 & $<0.001$ & 0.08 & & \\
\hline Perceived physical activity by child & -0.83 & $<0.001$ & 0.07 & & \\
\hline
\end{tabular}

Values shown in bold were significant $(P<0.05)$

${ }^{*}$ Reference group is New Zealand European and Others.

†Reference group is low.

‡Reference group is some secondary.

$\S$ Concerned $v$. not concerned.

IOverweight $v$. about right.

IOn a scale from 1 ('much less active') to 5 ('much more active').

because of the high multicollinearity between these measures. Only that for counts per minute is shown here but results from the other regression models were comparable. In total, these variables explained a large proportion of the variance in MSM weight score (69\%). Age, sex, maternal education and physical activity were no longer significant. Particularly large effects were observed for parental perception of weight status and concern about weight, with relatively smaller contributions from child BMI and food restriction. For example, parents who were concerned about their child's weight scored 2.5 units higher (almost $1 \mathrm{sD}$ ) on the MSM than those who were not concerned, with a difference of approximately 1.6 units for parents who classified their child as overweight compared with those who thought they were 'about right'. Comparable differences in motivation for weight score of $0.7-0.8$ were noted for 1-unit differences in actual weight status of children (one BMI $Z$-score) or food restriction (on a possible scale of 1-5). Because motivation for changing the child's weight was so highly correlated with parental concern $(r=0.76, P<0.001)$ and perception $(r=0.63$,
$P<0.001)$ of weight status, multivariate analyses were also undertaken excluding these two variables from the model. This alternative model still explained $52 \%$ of the variance in motivation, with age $(P=0.008)$, sex $(P<0.001)$, BMI $Z$-score $(P<0.001)$, food restriction $(P<0.001)$ and physical activity $(P=0.014)$ remaining significant predictors, and lifestyle behaviour score $(P=0.537)$ and maternal education $(P=0.09)$ no longer being significant.

\section{Discussion}

Our results demonstrate that parental motivation to change body weight in a community-based sample of young overweight children is low, with only $8 \%$ of parents actively trying to influence their child's weight. As expected, motivation was higher in children with greater degrees of overweight. However, even when restricted just to those with BMI values greater than the 97th percentile, only fourteen of sixty-seven parents (21\%) were actively trying to change their child's weight, despite 
virtually all (84\%) of these parents perceiving their child as overweight. While this apparent lack of motivation may seem surprising, others have clearly shown that parents are not concerned about excess weight in young children until it really starts to impede their mental or physical health $^{(4)}$. The dichotomy between parental ratings of the BMI values that suggest intervention is required, and that of expert committees, has been demonstrated previously $^{(24,25)}$. Over $70 \%$ of parents reported that the 90th BMI percentile is the minimum point at which weight management should be initiated, of whom one in five indicated that intervention should not happen until above the 97th percentile ${ }^{(24)}$. Similarly, a large Australian study could not demonstrate a discernible threshold above which mothers reliably became concerned about their young child's weight ${ }^{(25)}$.

Parents indicated greater motivation to change weight in girls compared with boys, despite no sex difference in relative weight status. This is perhaps because mothers are more likely to identify ${ }^{(26,27)}$ or be concerned ${ }^{(28,29)}$ about overweight in daughters compared with sons. Presumably, this reflects differing social values reflecting greater acceptance of overweight in boys relative to girls ${ }^{(30)}$. Greater motivation scores were also apparent when parents recognised there was a weight issue and/or were concerned about it. This is not surprising given there would be no desire to change weight if parents did not perceive their child as overweight, or at least were not concerned about it. How parents perceive the child's weight, whether they are concerned about it and their motivation to change weight are obviously interrelated variables of interest. While no studies appear to have examined correlates of parental motivation for changing weight in overweight children per se, studies have identified several factors predicting increased concern about weight in children including age (older $v$. younger) and sex (girls compared with boys) ${ }^{(29,31)}$, parental body size ${ }^{(7)}$, parents with a vested interest (overweight themselves) ${ }^{(32)}$, body fat distribution and intake of sweet drinks ${ }^{(33)}$. Similarly, poorer maternal accuracy regarding children's weight status has been associated with maternal education, maternal BMI, lower physical activity and rapid weight gain in infancy ${ }^{(34)}$.

Motivation was also higher in parents who perceived their child to have more problem behaviours as indicated by higher scores on the Lifestyle Behaviour Checklist ${ }^{(22)}$, those who were less physically active and parents who reported a greater degree of food restriction. It is interesting that motivation was higher in children who recorded significantly lower participation in physical activity. In practice, however, these differences are very small, not clinically relevant and were no longer significant in multivariate analyses. Restriction refers to the parent limiting and regulating a child's access to less healthy foods. Although this was initially thought to increase the risk of obesity $^{(35,36)}$, more recently work has demonstrated that maternal restriction is associated with lower BMI scores three years later, at least in younger children ${ }^{(37)}$. Thus parents who believe their child overeats might use restrictive feeding practices as a way of controlling that eating. Our observation that motivation was associated with restriction fits with other work demonstrating that concern is associated with restriction ${ }^{(35,38,39)}$. However in our sample, restriction remained a significant correlate of motivation even when adjusted for parental concern about weight.

Interestingly, parents were far more receptive towards changing diet and exercise habits in their children compared with changing weight. Discussions around target behaviours obviously provide an indirect means for health professionals to use as a focus for making important changes that do not address weight directly, but should have positive impact. It may be easier to engage parental motivation and action with diet and activity as a focus rather than weight, which may address concerns health professionals have about managing weight issues without damaging doctor/parent relationships ${ }^{(40,41)}$. Greater parental intention to change diet or activity (relative to weight) was not a function of social desirability, with no significant correlations between social desirability and any motivation score. This is important given that misreporting of dietary intake and physical activity has been associated with social desirability in children ${ }^{(42)}$ and parents ${ }^{(43)}$.

The strengths of our study include the use of a community-based sample, rather than a treatment-seeking population, and the assessment of motivation and other variables of interest before feedback of weight status occurred. Our parents were predominantly unaware of the weight status of their young child and the only information provided about the purpose of the study at recruitment was that it was for screening purposes. Although we did not recruit in a truly representative manner, we did purposively recruit a wide section of general practices, resulting in a final study sample with very few demographic differences from the wider local population ${ }^{(12)}$.

Thus the low levels of parental motivation for changing the weight of their overweight child that we observed do provide cause for concern. Recognition an issue exists is considered the first step in making appropriate behaviour change $^{(44)}$. Yet recognition alone is obviously not enough given our marked difference in those who rated their child as overweight ( $41 \%$ ) compared with those who were actively trying to change it ( $8 \%$ ). It appears that parents are more amenable and prepared to consider changing diet and activity than weight, which provides a useful pathway for health professionals to take when addressing overweight in young children. This may, at least in part, reflect the success of long-term public health campaigns promoting the importance of a healthy diet and regular physical activity for optimal development. Whether similar campaigns aimed at re-educating the general public about what (un)healthy weight looks like at different developmental 
stages would positively affect parental recognition and motivation for addressing overweight in their children is a question for future research. Despite higher levels of motivation for making dietary change, our results demonstrated a real dichotomy between parental views of their level of motivation to change diet and actual dietary behaviour, reflecting the complexity of the relationship between motivation and action. Further research investigating why parents do not appear motivated to change the weight of their overweight child should provide much-needed insight into how best to encourage healthy lifestyles for all young children ${ }^{(45)}$.

\section{Acknowledgements}

Financial support: This research was funded by the Health Research Council of New Zealand (grant number 09/087B). The Health Research Council had no role in the design, analysis or writing of this article. Conflicts of interest: None. Authorship: R.W.T. is Principal Investigator of the MInT study; she conceived of the idea for the paper and wrote the first and subsequent drafts of the manuscript. S.M.W. designed and completed all statistical analyses. A.M.D., J.J.H. and D.A.B. contributed to study design and data collection. All authors contributed to writing of the manuscript. Ethics of human subject participation: This study was approved by the Lower South Regional Ethics Committee (LRS/09/09/039).

\section{References}

1. Faith MS, Van Horn L, Appel L et al. (2012) Evaluating parents and adult caregivers as 'agents of change' for treating obese children. Evidence for parent behavior change strategies and research gaps. A scientific statement from the American Heart Association. Circulation 125, 1186-1207.

2. Miller J, Grant AM, Drummond BF et al. (2007) DXA measurements confirm parental perceptions of elevated adiposity in young children are poor. Obesity (Silver Spring) 15, $165-171$.

3. Doolen J, Alpert PR \& Miller SK (2009) Parental disconnect between perceived and actual weight status of children: a metasynthesis of the current research. J Am Acad Nurse Pract 21, 160-166.

4. Jain A, Sherman SN, Chamberlin LA et al. (2001) Why don't low-income mothers worry about their preschoolers being overweight? Pediatrics 107, 1138-1146.

5. Miller WR \& Johnson WR (2008) A natural language screening measure for motivation to change. Addict Behav 33, $1177-1182$.

6. Miller WR \& Rollnick S (2008) Motivational Interviewing in Health Care: Helping Patients Change Behavior. New York: Guilford Press.

7. Rhee KE, DeLago CW, Arscott-Mills T et al. (2005) Factors associated with parental readiness to make changes for overweight children. Pediatrics 116, e94-e101.

8. Campbell M, Benton JM \& Werk LN (2011) Parent perceptions to promote a healthier lifestyle for their obese child. Soc Work Health Care 50, 787-800.
9. Gunnarsdottir T, Njardvik U, Olafsdottir AS et al. (2011) The role of parental motivation in family-based treatment for childhood obesity. Obesity (Silver Spring) 19, 1654-1662.

10. Dhingra A, Brennan L \& Walkley J (2011) Predicting treatment initiation in a family-based adolescent overweight and obesity intervention. Obesity (Silver Spring) 19, 1307-1310.

11. Taylor RW, Williams SM, Dawson AM et al. (2013) What factors influence uptake into family-based obesity treatment after weight screening? J Pediatr 163, 1657-1662.e1.

12. Dawson AM, Brown DA, Cox A et al. (2014) Using motivational interviewing for weight feedback to parents of young children. J Paediatr Child Health 50, 461-470.

13. Taylor RW, Brown D, Dawson AM et al. (2010) Motivational interviewing for screening and feedback and encouraging lifestyle changes to reduce relative weight in 4-8 year old children: design of the MInT study. BMC Public Health 10, 271.

14. Kuczmarski RJ, Ogden CL, Guo SS et al. (2002) 2000 CDC growth charts for the United States: methods and development. Data from the National Health Survey. Vital Health Stat 11 issue 246, 1-190.

15. White P, Gunston J, Salmon C et al. (2008) Atlas of Socioeconomic Deprivation in New Zealand NZDep2006. Wellington: Ministry of Health.

16. Haszard JJ, Williams SM, Dawson AM et al. (2013) Factor analysis of the Comprehensive Feeding Practices Questionnaire in a large sample of children. Appetite 62, 110-118.

17. Musher-Eizenman D \& Holub S (2007) Comprehensive feeding practices questionnaire: validation of a new measure of parental feeding practices. J Pediatr Psychol 32, 960-972.

18. Arnold DS, O'Leary SG, Wolff LS et al. (1993) The Parenting Scale: a measure of dysfunctional parenting and discipline situations. Psychol Assess 5, 137-144.

19. Reynolds W (1982) Development of reliable and valid short forms of the Marlowe-Crowne Social Desirability Scale. J Clin Psychol 83, 119-125.

20. Magarey A, Golley R, Spurrier N et al. (2009) Reliability and validity of the Children's Dietary Questionnaire; a new tool to measure children's dietary patterns. Int J Pediatr Obes $\mathbf{4}$, $257-265$.

21. Matheny AP, Wachs TD, Ludwig JL et al. (1995) Bringing order out of chaos: psychometric characteristics of the confusion, hubbub and order scale. J Appl Dev Psychol 16, 429-444.

22. West F \& Sanders MR (2009) The Lifestyle Behaviour Checklist: a measure of weight-related problem behaviour in obese children. Int J Pediatr Obes 4, 266-273.

23. Evenson KR, Catellier DJ, Gill K et al. (2008) Calibration of two objective measures of physical activity for children. J Sports Sci 26, 1557-1565.

24. Warschburger P \& Kroller K (2012) Childhood overweight and obesity: maternal perceptions of the time for engaging in child weight management. BMC Public Health 12, 295.

25. Wake M, Canterford L, Hardy P et al. (2011) At what BMI are parents of pre-schoolers concerned? National crosssectional study. Int J Pediatr Obes 6, 499-501.

26. Jeffery AN, Voss LD, Metcalf BS et al. (2005) Parents' awareness of overweight in themselves and their children: cross sectional study within a cohort (EarlyBird 21). BMJ 330, 23-24.

27. Vanhala ML, Keinanen-Kiukaanniemi SM, Kaikkonen KM et al. (2011) Factors associated with parental recognition of a child's overweight status - a cross sectional study. BMC Public Health 11, 665.

28. Campbell M, Williams J, Hampton A et al. (2006) Maternal concern and perceptions of overweight in Australian preschool-aged children. Med J Aust 184, 274-277. 
29. Moore LC, Harris CV \& Bradlyn AS (2012) Exploring the relationship between parental concern and the management of childhood obesity. Matern Child Health J 16, 902-908.

30. Maynard LM, Galuska DA, Blanck HM et al. (2003) Maternal perceptions of weight status of children. Pediatrics 111, 1226-1231.

31. Baughcum AE, Chamberlin LA, Deeks CM et al. (2000) Maternal perceptions of overweight preschool children. Pediatrics 106, 1380-1386.

32. Carnell S, Edwards C, Croker H et al. (2005) Parental perceptions of overweight in 3-5 y olds. Int J Obes (Lond) 29, 353-355.

33. Keller KL, Olsen A, Kuilema L et al. (2013) Predictors of parental perceptions and concerns about child weight. Appetite 62, 96-102.

34. Manios Y, Moschonis G, Grammatikaki E et al. (2010) Determinants of childhood obesity and associated with maternal perceptions of their children's weight status: the 'GENESIS' study. J Am Diet Assoc 110, 1527-1531.

35. Birch LL, Fisher JO \& Davison KK (2003) Learning to overeat: maternal use of restrictive feeding practices promotes girls' eating in the absence of hunger. Am J Clin Nutr 78, 215-220.

36. Faith MS, Berkowitz RI, Stallings VA et al. (2004) Parental feeding attitudes and styles and child body mass index: prospective analysis of a gene-environment interaction. Pediatrics 114, e429-e436.

37. Campbell K, Andrianopoulos N, Hesketh K et al. (2010) Parental use of restrictive feeding practices and child BMI z-score. A 3-year prospective cohort study. Appetite 55, 84-88.
38. Birch LL, Fisher JO, Grimm-Thomas K et al. (2001) Confirmatory factor analysis of the Child Feeding Questionnaire: a measure of parental attitudes, beliefs and practices about child feeding and obesity proneness. Appetite 36, 201-210.

39. Webber L, Hill C, Cooke L et al. (2010) Associations between child weight and maternal feeding styles are mediated by maternal perceptions and concerns. Eur J Clin Nutr 64, 259-265.

40. He M, Piche L, Clarson CL et al. (2010) Childhood overweight and obesity management: a national perspective of primary health care providers' views, practices, perceived barriers and needs. Paediatr Child Health 15, 419-426.

41. Banks J, Sheild JPH \& Sharp D (2011) Barriers engaging families and GPs in childhood weight management strategies. Br J Gen Pract 61, e492-e497.

42. Klesges LM, Baranowski T, Beech B et al. (2004) Social desirability bias in self-reported dietary, physical activity and weight concerns measures in 8- to 10-year-old AfricanAmerican girls: results from the Girls Health Enrichment Multiside Studies (GEMS). Prev Med 38, Suppl., S78-S87.

43. Börnhorst C, Huybrechts I, Ahrens W et al. (2013) Prevalence and determinants of misreporting among European children in proxy-reported $24 \mathrm{~h}$ dietary recalls. $\mathrm{Br} \mathrm{J} \mathrm{Nutr}$ 109, 1257-1265.

44. Barlow SE, Bobra SR, Elliott MB et al. (2007) Recognition of childhood overweight during health supervision visits: does BMI help pediatricians? Obesity (Silver Spring) 15, 225-232.

45. Gruber KJ \& Haldeman LA (2009) Using the family to combat childhood and adult obesity. Prev Chronic Dis 6, A106. 